\title{
Bone and joint infections in adults: a comprehensive classification proposal
}

\author{
Carlo Luca Romanò • Delia Romanò • Nicola Logoluso • \\ Lorenzo Drago
}

Received: 14 January 2011 / Accepted: 31 March 2011 /Published online: 14 April 2011

(C) The Author(s) 2011. This article is published with open access at Springerlink.com

\begin{abstract}
Introduction and methods Ten currently available classifications were tested for their ability to describe a continuous cohort of 300 adult patients affected by bone and joint infections. Each classification only focused, on the average, on $1.3 \pm 0.4$ features of a single clinical condition (osteomyelitis, implant-related infections, or septic arthritis), being able to classify $34.8 \pm 24.7 \%$ of the patients, while a comprehensive classification system could describe all the patients considered in the study.

Result and conclusion A comprehensive classification system permits more accurate classification of bone and joint infections in adults than any single classification available and may serve for didactic, scientific, and clinical purposes.
\end{abstract}

Keywords Bone and joint infections (BJIs) .

Osteomyelitis · Implant-related infection · Septic arthritis .

Joint infection

\section{Introduction}

The term osteomyelitis was first used by the French surgeon Edouard Chassaignac in 1852 [1], who defined the disease as

C. L. Romanò $(\varangle) \cdot$ D. Romanò $\cdot$ N. Logoluso

Dipartimento di Chirurgia Ricostruttiva e delle Infezioni

Osteo-articolari, Istituto Ortopedico I.R.C.C.S. Galeazzi,

Via Riccardo Galeazzi,

4-20161 Milan, Italy

e-mail: carlo.romano@grupposandonato.it

L. Drago

Laboratorio Analisi e Microbiologia,

Istituto Ortopedico I.R.C.C.S. Galeazzi,

Via R. Galeazzi,

4-20161 Milan, Italy an inflammatory process accompanied by bone destruction and caused by an infecting microorganism.

In the past, osteomyelitis infections were mainly the results of direct bacterial penetration into the bone or adjacent tissues, through soft tissue lesions secondary to low-energy traumas (wounds, falls, punctures, bites, etc.) or to hematogenous spreading of the microorganisms from septic foci localized in other organs and apparatus. While those mechanisms of bacterial colonization of the bone tissue have not disappeared, especially in the industrialized world and during the last century, a progressive increase of bone and joint infections (BJIs) due to high-energy traumas (wars, traffic, sports, etc.) or secondary to surgical procedures has been observed. Besides this, more and more osteomyelitis and septic arthritis today are found to be causally related with dismetabolisms (diabetes, renal insufficiency, etc.), peripheral vasculopathies and neuropathies, life habits (smoking, drug, or alcohol abuse), inherited or acquired immunodeficiencies, and advanced age. On the other hand, over the past decades, a tremendous progress in the knowledge and treatment of the different types of BJIs has been made, and many factors that account for the occurrence and persistence of this disease have now been identified [2,3]. New operative techniques and a variety of antimicrobials with different spectrums of activity against specific pathogens have also been developed and their use recommended for specific clinical presentation of BJIs.

In this complex panorama, a single universally accepted classification system of BJIs is not available [4]. In fact, even the most commonly used classifications only focus on one or few aspects (etiology, anatomo-pathology, host type, etc.) of single specific pathological conditions, like osteomyelitis [5-8], periprosthetic infection [9, 10], or septic arthritis [11], being thus unable to represent any given patient affected by BJIs. 
The aim of the present paper is to discuss, in the light of the available literature and classifications, the most relevant items that are required to characterize BJIs in adults and to propose a unique, comprehensive classification of BJIs.

\section{Methods}

We searched MEDLINE, EMBASE, and the principal Internet search engines (www.google.com, www.yahoo. com, www.ask.com, www.bing.com) for general keywords such as "classification," "staging," "infection," "bone," "joint," "osteomyelitis," both isolated or in combination, from 1970 until present. We also included previous classification proposals published in the Italian literature and here briefly summarized in English. The reference list of studies which met the inclusion criteria was further screened for inclusion of manuscripts which could have been omitted from the initial screening process.

To further understand the specificity of the available retrieved classifications, they were divided according to the main object basis of classification and the classified items.

The retrieved classifications and a new comprehensive classification system were then tested and compared for the ability to describe the clinical condition of a continuous cohort of 300 adult patients affected by bone and joint infections who were treated surgically in our department during years 2008-2009.

\section{Results}

The review of the available literature confirms BJIs as a complex group of diseases, for which various classification systems have emerged in the past four decades. A total of ten classifications dealing with a clinical manifestation of BJIs were retrieved. A summary of the content of each of them is reported in Table 1.

The average age of all the classification systems, from the first year of publication to present, is $21.4 \pm 11.6$ years (maximum, 40; minimum, 4 years). Seven out of ten classifications were published more than 20 years ago.

The two main variables studied by the available classification systems of BJIs are: (1) the type of nosological entity (osteomyelitis, implant-related infections, and septic arthritis) and (2) a particular feature (item) of that nosological entity.

Considering the ten classifications retrieved, we may observe that five classification systems are focused only on osteomyelitis, three on implant-related infections, one on septic arthritis, while one classification includes all the three nosological entities, even if dealing with a single peculiar aspect of the infection (bone defects).

Overall, seven items that characterize BJIs have been described by one or more classification system: clinical presentation, etiopathogenesis, anatomo-pathology, host, microorganism, bone defect, and soft tissues. The mean number of items categorized by any single classification is $1.3 \pm 0.4$ (range, 1 to 2 ).

A brief description of the seven items, the way they are classified by the respective systems, and some more data concerning their relevance with regard to BJIs are provided below.

\section{Clinical presentation}

Historically, osteomyelitis has been categorized as acute, subacute, or chronic based on the time of disease onset (i.e., occurrence of infection or injury). The duration of symptoms of infection is in fact associated with peculiar anatomo-pathological findings and clinical and diagnostic features, and influences the therapeutic decisions $[10,12-15]$.

Acute osteomyelitis is diagnosed within 2 weeks after disease onset, subacute osteomyelitis within one to several months, and chronic osteomyelitis after a few months [12, 16]. Acute osteomyelitis occurs predominantly in children, with the metaphysis of long bones the most common location. Patients usually present within several days to 1 week after the onset of symptoms. In addition to local signs of inflammation and infection, patients have signs of systemic illness, including fever, irritability, and lethargy. Typical clinical findings include tenderness over the involved bone and decreased range of motion in adjacent joints. The subacute and chronic forms of osteomyelitis usually occur in adults. Generally, these bone infections are secondary to an open wound, most often an open injury to bone and surrounding soft tissue. Localized bone pain, erythema, and drainage around the affected area are frequently present. The cardinal signs of subacute and chronic osteomyelitis include draining sinus tracts, deformity, instability and local signs of impaired vascularity, range of motion, and neurologic status.

Analogously, periprosthetic infections have been classified according to time of onset after surgery as early, delayed, or late. Early manifestation is generally defined as the appearance of the first signs and symptoms of infection during the first 4-12 weeks post-surgery, according to different authors. Delayed manifestation is defined as an infection in which the first signs and symptoms appear between 3 months and 2 years postsurgery, and late manifestation is defined as the appearance of the first signs and symptoms of infection $>2$ years post-surgery $[10,17,18]$. 
Table 1 Classifications of bone and joint infections published in the last four decades

\begin{tabular}{|c|c|c|c|}
\hline Authors & $\begin{array}{l}\text { Year of first } \\
\text { publication }\end{array}$ & $\begin{array}{l}\text { Main object of } \\
\text { classification }\end{array}$ & Classified items \\
\hline Waldvogel et al. & 1970 & Osteomyelitis & $\begin{array}{l}\text { Duration } \\
\text { Acute } \\
\text { Chronic } \\
\text { Etiopathogenesis } \\
\text { Hematogenous osteomyelitis } \\
\text { Osteomyelitis secondary to contiguous focus of } \\
\text { infection } \\
\text { No generalized vascular disease } \\
\text { Generalized vascular disease }\end{array}$ \\
\hline Ger R. & 1977 & Osteomyelitis & $\begin{array}{l}\text { Soft tissue } \\
\text { Type I, simple sinus } \\
\text { Type II, chronic superficial ulcer } \\
\text { Type III, multiple sinuses } \\
\text { Type IV, multiple skin-lined sinuses }\end{array}$ \\
\hline Cierny and Mader & 1984 & Long bone osteomyelitis & $\begin{array}{l}\text { Anatomo-pathological } \\
\text { Stage 1, medullary osteomyelitis } \\
\text { Stage 2, superficial osteomyelitis } \\
\text { Stage 3, localized osteomyelitis } \\
\text { Stage 4, diffuse osteomyelitis } \\
\text { Host } \\
\text { Type A, normal } \\
\text { Type B, compromised (local and/or systematic) } \\
\text { Type C, treatment worse than the disease }\end{array}$ \\
\hline Kelly et al. & 1984 & Osteomyelitis & $\begin{array}{l}\text { Etiopathogenesis } \\
\text { Hematogenous osteomyelitis } \\
\text { Posttraumatic (united fracture) } \\
\text { Posttraumatic (nonunited fracture) } \\
\text { Post-surgical } \\
\text { Anatomo-pathological } \\
\text { Type I, open, without evidence of bone infection } \\
\text { Type II, circumferential, cortical, and endosteal } \\
\text { infection } \\
\text { Type III, cortical and endosteal infection associated } \\
\text { with segmental bone }\end{array}$ \\
\hline Gächter A. & 1985 & Septic arthritis (knee) & $\begin{array}{l}\text { Anatomo-pathological } \\
\text { Stage I, opacity of fluid, redness of the synovial } \\
\text { membrane, no radiographic changes } \\
\text { Stage II, severe inflammation, fibrinous deposition, } \\
\text { pus, no radiological changes } \\
\text { Stage III, thickening of the synovial membrane, } \\
\text { compartment formation, no radiological changes } \\
\text { Stage IV, aggressive pannus with infiltration of the } \\
\text { cartilage, undermining the cartilage, radiological signs } \\
\text { of subchondral osteolysis, possible osseous erosions, } \\
\text { and cysts }\end{array}$ \\
\hline Gordon et al. & 1988 & Osteomyelitis (tibia) & $\begin{array}{l}\text { Bone defect } \\
\text { Type A, tibial defects and nonunions without } \\
\text { significant segmental loss } \\
\text { Type } \mathrm{B} \text {, tibial defects of }<3 \mathrm{~cm} \text {, intact fibula } \\
\text { Type } \mathrm{C} \text {, tibial defects of }>3 \mathrm{~cm} \text {, no intact fibula }\end{array}$ \\
\hline
\end{tabular}


Table 1 (continued)

\begin{tabular}{|c|c|c|c|}
\hline Authors & $\begin{array}{l}\text { Year of first } \\
\text { publication }\end{array}$ & $\begin{array}{l}\text { Main object of } \\
\text { classification }\end{array}$ & Classified items \\
\hline McPherson et al. & 2002 & $\begin{array}{l}\text { Implant-related infections } \\
\text { (hip prosthesis) }\end{array}$ & $\begin{array}{l}\text { Duration } \\
\text { I, early postoperative ( }<4 \text { weeks from surgery) } \\
\text { II, hematogenous ( }<4 \text { weeks duration) } \\
\text { III, late chronic ( }>4 \text { weeks duration) } \\
\text { Host } \\
\text { Type A, uncompromised } \\
\text { Type B, compromised (one to two compromising factors) } \\
\text { Type C, significantly compromised (more than two } \\
\text { compromising factors) }\end{array}$ \\
\hline Romanò et al. & 2006 & $\begin{array}{l}\text { Osteomyelitis } \\
\text { Septic arthritis } \\
\text { Implant-related infections }\end{array}$ & $\begin{array}{l}\text { Bone defect } \\
\text { Type } 1 \text {, cavitary defect } \\
\text { Type } 2 \text {, epiphyseal defect } \\
\text { Type } 3 \text {, segmental defect }\end{array}$ \\
\hline Romanò et al. & 2006 & $\begin{array}{l}\text { Implant-related infections } \\
\text { (osteosynthesis) }\end{array}$ & $\begin{array}{l}\text { Anatomo-pathological } \\
\text { Type I, stable osteosynthesis, with callus progression } \\
\text { Type II, stable osteosynthesis, with scarce or absent } \\
\text { callus progression } \\
\text { Type III, no callus formation and unstable } \\
\text { osteosynthesis }\end{array}$ \\
\hline
\end{tabular}

\section{Etiopathogenesis}

Etiopathogenesis of BJIs has a clear importance as regards the natural history, epidemiology, diagnostic, and treatment modalities.

The Waldvogel classification system [8, 12] divides osteomyelitis not only on the basis of duration but also according to the pathogenesis into: secondary to a contiguous focus (trauma, surgery, or insertion of a joint prosthesis), secondary to vascular insufficiency, and hematogenous.

Hematogenous osteomyelitis is predominantly encountered in the pediatric population. In children, hematogenous infection usually affects the long bones, while in adults, the lesion is usually located in the thoracic or lumbar vertebrae. Osteomyelitis secondary to a contiguous focus of infection can derive either from a direct infection of bone from a source outside the body (e.g., soft tissue trauma, open fracture, or surgery) or from the continuous spread of infection from an ulceration, adjacent focus (e.g., soft tissue infection, dental abscess, or decubitus ulcer). Osteomyelitis associated with vascular insufficiency as described by Waldvogel was mainly due to diabetes (diabetic foot); however, it can be caused by atherosclerosis, vasculitis, etc.

Kelly proposed a similar etiopathogenetic classification of osteomyelitis in the adult, divided into four categories: hematogenous, osteomyelitis in a united fracture (fracture with union), osteomyelitis in a nonunion fracture (fracture with nonunion), and postoperative osteomyelitis without fracture [19]. Kelly's classification system emphasized the etiology of the infection and its relationship to fracture healing.

More recently, a pathogenetic role of neuropathy has been demonstrated [20], and this component should probably be included in a modern classification of osteomyelitis based on etiopathogenesis.

On the other hand, post-surgical infections have been differentiated, in the last years, on the basis of the presence/ absence of implanted materials. Implant-related infections are probably the most relevant burden of BJIs in the developed countries $[21,22]$ and possess peculiar pathogenetic, diagnostic, and therapeutic features that clearly differentiate them from other conditions in which no foreign material is present. Implant-related infections are in fact characterized by challenging diagnosis and treatment, due to the particular ability of bacteria to adhere to the surface of the implanted hardware. It is largely demonstrated how bacteria, after adhering to a surface, become able to produce a polysaccharidic biofilm that protects the pathogens from immunological response and antibiotic activity and make them behave like a multicellular organism [2, 3, 22, 23]. The presence of biofilm usually makes it necessary to remove the implant to obtain the healing from infection. Considering implant-related infections, a further difference may be retrieved between permanently implanted materials (e.g., total joint prosthesis) and temporary implant materials (e.g., osteosynthesis, nails, plates, etc.). While, in fact, a prosthesis has been designed to stay in the body forever and the removal of an infected 
prosthesis determines a loss of function of the joint, osteosynthesis and fixation materials are intended for a temporary use and only needed until bone healing takes place.

To our knowledge, there are no published classifications of infections after osteosynthesis in the English literature. Few years ago, we proposed a simple classification system ("ICS Classification," from the acronym of Infection, Callus, Stability) [24] based on the observation that infection may slow callus formation but does not prevent, in itself, bone healing [25-27]; according to this classification, three conditions can be distinguished:

- Type I: infection in the presence of a stable osteosynthesis, with callus progression at X-ray examinations. The treatment in these cases may be conservative, controlling the infection with medico-surgical procedures, allowing until bone healing. Hardware removal is then performed after fracture healing.

- Type II: presence of infection in a stable osteosynthesis, with scarce or absent callus progression. In those cases, the synthesis can be maintained, controlling the infection as for type I, accelerating bone healing through physical stimulation (low-intensity pulsed ultrasound [28], electromagnetic fields, etc.), biological factors (bone morphogenetic protein, platelet rich plasma, etc.), and limited surgical procedures (e.g., dinamization).

- Type III: infection, no callus formation, and unstable osteosynthesis. In these cases, synthesis removal and change of the fixation device are required.

\section{Anatomo-pathological findings}

Anatomo-pathological aspects of each BJI are among the most important determinants of the treatment strategy and of the success rate. The simple site of infection - that we may here divide into long bones, joints, rachis, hand, footstrongly determines the treatment choice, due to the relevant difference in vascularity, soft tissue coverage, function, and possible treatment options. For this reason, a clear definition of the localization BJIs in various patients should be mandatory.

In this regard, however, we only found more detailed anatomo-pathological classifications of BJIs for osteomyelitis of the long bones and for septic arthritis of the knee.

Weiland [29] defined chronic osteomyelitis as a wound with exposed bone, positive bone cultures, and drainage for $<6$ months. A similar wound with drainage of less than 6 months was not considered to be a site of chronic osteomyelitis. He further divided the infection on the basis of soft tissue and the location of bone involved. Type I osteomyelitis was defined as open, exposed bone without evidence of osseous infection but with evidence of soft tissue infection. Type II osteomyelitis showed circumferen- tial, cortical, and endosteal infection. The radiographs demonstrated a diffuse inflammatory response, increased bone density, and spindle-shaped sclerotic thickening of the cortex. Other radiographic findings included areas of bony resorption and often a sequestrum with a surrounding involucrum. Type III osteomyelitis revealed cortical and endosteal infection associated with a segmental bone defect.

The Cierny-Mader classification [5-7, 30] is a wellknown clinical classification based on anatomic, clinical, and radiologic features. From the anatomo-pathological point of view, it characterizes osteomyelitis as being in one of four anatomic stages. In stage 1, or medullary, osteomyelitis is confined to the medullary cavity of the bone. Stage 2, or superficial, osteomyelitis involves only the cortical bone and most often originates from a direct inoculation or a contiguous focus infection. Stage 3, or localized, osteomyelitis usually involves both cortical and medullary bones. In this stage, the bone remains stable, and the infectious process does not involve the entire bone diameter. Stage 4, or diffuse, osteomyelitis involves the entire thickness of the bone, with loss of stability, as in infected nonunion. The authors showed how each stage may require an appropriate and different treatment strategy, and this classification is then useful for decision making.

Cierny and DiPasquale tried to adjust the Cierny-Mader classification system for osteomyelitis in adult patients also for the classification of periprosthetic total joint infections [9]. In this system, prosthetic joint infections are entered as anatomic types of the disease: early and superficial osteomyelitis (type II) or late and refractory osteomyelitis (type IV of the initial osteomyelitis staging system). Besides this anatomic differentiation, the authors added local and systemic host factors that may affect treatment and prognosis.

Septic arthritis has also been classified according to their morphological aspect. The classification system, first described by Gächter [11] for the knee, seems applicable also to other joints [31]. This classification system consists of four stages and combines intra-articular findings in the soft tissues as well as radiological alterations of the infected joint:

- Stage I: opacity of fluid, redness of the synovial membrane, possible petechial bleeding, no radiological alterations

- Stage II: severe inflammation, fibrinous deposition, pus, no radiological alterations

- Stage III: thickening of the synovial membrane, compartment formation, no radiological alterations

- Stage IV: aggressive pannus with infiltration of the cartilage, undermining the cartilage, radiological signs of subchondral osteolysis, possible osseous erosions, and cysts. According to the Author, infections classified up to stage III can be arthroscopically treated, whereas stage IV requires open revision surgery. 


\section{Host type}

Host is one of the most relevant factors both concerning susceptibility to develop BJIs and prognosis of the disease.

We have already mentioned how acute, subacute, and chronic osteomyelitis occur with different frequency in different ages. Age is not only connected with the occurrence of hematogenous infection, but extremes of age also play a role in the immunological response and prognosis of BJIs [32].

The Cierny-Mader system was the first to include host type classification $[6,30,33]$. According to this classification, the A-hosts are patients without systemic or local compromising factors, B-hosts are affected by one or more local and/or systemic compromising factors, and C-hosts are patients so severely compromised that the radical surgical treatment necessary would have an unacceptable risk-benefit ratio. One shortfall of this system is that, by definition, the C-host category is a subjective evaluation, since the indication to a given surgical procedure is influenced not only by the patient's comorbidities, but, to a great extent, also by hospital facilities, surgeon's skill and self-confidence, previous experience, etc.

In this regard, the most recent classification proposed by McPherson and co-workers [30] provides a more clear and standardized system for host definition that the author proposes a part of their classification of periprosthetic hip infection. Compromising factors are similar to those proposed by Cierny-Mader; however, according to the system from McPherson, patients are divided in A, uncompromised, normal hosts; in $\mathrm{B}$, compromised hosts, with one to two local and/or systemic compromising factors; in $\mathrm{C}$, significant compromise, with more than two compromising factors. This definition is obviously more reproducible and not influenced by the treatment indication.

\section{Microorganism}

The correct definition of the infecting agent and its antibiotic resistance drives the medical approach, correlates with the prognosis and to the natural history of each BJI. Ure et al. emphasized that a directexchange arthroplasty can only be carried out in early infections and if the infecting organism is of low virulence (no methicillin-resistant or gram-negative bacteria) [34].

Moreover, the resistance profile of the causative bacterium might be associated with prolonged and complicated treatment courses. Kilgus et al. evaluated periprosthetic hip joint infections caused by antibiotic-sensitive and antibiotic-resistant bacteria [35]. The authors concluded that hip replacements infected with antibiotic-sensitive bacteria were treated successfully in $81 \%$ of the cases, whereas arthroplasties infected with resistant bacteria were treated successfully in only $48 \%$ of the cases.

Depending on the causative pathogen organism, infections can be divided into bacterial, mycotic, and fungal ones. Bacterial infections can be further classified as gram-positive or gram-negative and mono- or multibacterial. Culturenegative infections pose special problems with regard to diagnosis, treatment choice, and patient compliance.

The specific microorganism(s) isolated from patients with bacterial osteomyelitis is often associated with the age of the patient or the clinical scenario. Staphylococcus aureus is implicated in most cases of acute hematogenous osteomyelitis and is responsible for up to $90 \%$ of cases in otherwise healthy children. Staphylococcus epidermidis, $S$. aureus, Pseudomonas aeruginosa, Serratia marcescens, and Escherichia coli are commonly isolated in patients with chronic osteomyelitis or implant-related infections.

Fungal infections are rare but commonly found in immunosuppressive patients and associated with complications and infection persistence [36]. A possible explanation for that might be the fact that a local antifungal therapy does not reach as high antimicrobial concentrations for longer periods as antibiotic-impregnated cement device in the treatment of bacterial infections do.

\section{Bone defect}

Bone defects are a common finding in osteoarticular infections. Bone loss may be the result of the infection per se, of previous trauma or surgery, of hardware loosening and removal, and of the necessary surgical necrotic and infected bone debridement. Classification of bone defects is relevant to the treatment strategy, as many different therapeutic options are today available, including antibiotic-loaded biomaterials [22, 37], modular revision prosthesis, orthopedic and plastic special procedures [3841], etc. Different classification systems have been proposed based on the site and extent of the bone defect; however, specific classifications for bone infections are remarkably few.

Different, detailed classifications have been, in fact, proposed to categorize bone defect in joint reconstruction after aseptic loosening of a joint prosthesis [42-45]. The use of these classifications may be extended to bone loss due to infection in revision surgery; however, no specific classification has been reported so far.

As to concerning long bones, Gordon [46] classified infected tibial nonunions and segmental defects on the basis of the osseous defects. Type A included tibial defects and nonunions without significant segmental loss. Type B included tibial defects of $<3 \mathrm{~cm}$ with an intact fibula. Type $\mathrm{C}$ included tibial defects of $>3 \mathrm{~cm}$ in patients whose fibula 
was not intact. Gordon's classification correlates with the prognosis for successful free-muscle transportation.

Few years ago, we proposed in the Italian literature a simple general classification of the bone defect that categorized bone defect [47] as follows:

- Type 1: cavitary defects. This common type of bone defect may occur in the context of a bone segment and is usually well delimited by a sclerotic bone. The volume of this defect may vary from few cubic millimeters to several cubic centimeters. The stability of the bone segment is maintained. Type 1 defects may be frequently observed in hematogenous infections, periprosthetic infections, and after osteosynthesis. They usually can be treated with local debridement and antibiotic-loaded fillers (either resorbable, like bone graft or bone substitutes, or non-resorbable, like polymethylmetacrylate) [22, 37];

- Type 2: is an epiphyseal defect. It features a total or partial bone loss at the joint level. It may be the result of a septic joint arthritis, septic osteosynthesis, or periprosthetic joint infection. The treatment usually consists of prosthetic implant, arthrodesis, arthroplasty, or amputation.

- Type 3: is a segmental bone defect. This is further divided into type $3 \mathrm{~A}$, when a gap between bone extremities is less than $1 \mathrm{~cm}$; type $3 \mathrm{~B}$, when the gap is less than $3 \mathrm{~cm}$ and more than $1 \mathrm{~cm}$; and type $3 \mathrm{C}$, when the gap is more than $3 \mathrm{~cm}$. Type 3 defects are, by definition, associated with a loss of bone stability. This type of defect may be retrieved in septic incomplete or nonunions, segmental bone resection after infection, etc. It may require external fixation with or without bone grafts, bone transport [48], segmental prosthesis, or vascularized bone grafts.

\section{Soft tissues}

Soft tissues play a major role in the prognosis and the treatment of BJIs, not only because bone exposition may clearly determine bone contamination, superinfection, and necrosis but also because the amount and quality of soft tissue are associated with local vascular support and tissue nutrition. To our knowledge, a systematic classification of soft tissues in BJIs has not been described.

Ger's classification system, published in 1977, addressed the physiology of the wound as it relates to osteomyelitis in a more detailed manner; his categories include: simple sinus, chronic superficial ulcer, multiple sinuses, and multiple skin-lined sinuses [49].

\section{The "Seven-Item Comprehensive Classification System"}

Most of the retrieved classifications of BJIs present a rather old age, only focus on a single clinical entity, and do not categorize more than two aspects (usually only one) of the disease under study at a time. These are, in our opinion, the main reasons why all the currently available classifications fail to provide a complete description of the vast universe of bone and joint infections that we face in the clinical practice. The way BJIs are not currently classified also explains how difficult it is for a common orthopedic surgeon or an infectivologist to approach this disease in a comprehensive manner and with a common vision and language.

In our review, based on the currently available classifications and on the data from the literature, we could identify at least seven items that all determine, to a different extent and with different modalities, the natural history, diagnosis, treatment, and prognosis of BJIs. The discrepancy between the number of the known relevant items and the number of those actually categorized by any single classification gives the measure of the incomplete description provided by all the existing classifications.

In fact, even considering two of the most sophisticated and recent classification systems, the one from CiernyMader [7, 30] and that from McPherson and co-workers [10], we may observe that they only focus on a maximum of two items and only in, respectively, osteomyelitis of the long bones and periprosthetic infections of the hip.

Our purpose, at the end of this review, was to present a comprehensive classification of BJIs. Instead of proposing a completely new classification, it seemed more appropriate, at this stage, to choose among the existing classifications the most reliable categorization of each of the seven selected items and put them into an organic classification system of the whole world of BJIs. This "Seven-Item Comprehensive Classification System (7 ICCS)" then includes the seven items described above, each one adequately categorized according to one of the existing classification, whenever possible (Table 2):

1. Clinical presentation. Our suggestion is to classify it as acute, subacute, or chronic, with the exception of implant-related infection, for which a distinction in early, delayed, and late seems more appropriate;

2. Etiopathogenesis. A modern classification should include hematogenous, dismetabolic (vasculopathic and/or neuropathic), posttraumatic, and implant-related (temporary or permanent) infections. As far as temporary implants are concerned, the ICS classification may prove useful for driving therapeutic decisions.

3. Anatomo-pathological aspects include a distinction between the site of the infection (rachis, hand, long bones, foot, and joints), while more detailed subclassifications are included for long bones, according to CiernyMader, and for joint infections, according to Gachter. 
Table 2 The seven items of the "Seven-Item Comprehensive Classification System" of bone and joint infections

\begin{tabular}{|c|c|c|c|c|c|c|c|}
\hline \multicolumn{2}{|c|}{ Clinical presentation } & \multirow{2}{*}{$\begin{array}{l}\text { Etiopathogenesis } \\
\text { Hematogenous }\end{array}$} & \multirow{2}{*}{$\begin{array}{l}\text { Anatomo-pathology } \\
\text { Rachis }\end{array}$} & \multirow{2}{*}{$\begin{array}{l}\begin{array}{l}\text { Host type/ } \\
\text { age }\end{array} \\
\mathrm{A}_{\mathrm{a}, \mathrm{c}, \mathrm{i}}\end{array}$} & \multirow{2}{*}{$\begin{array}{l}\text { Microorganism } \\
\text { Gram+ }\end{array}$} & \multirow{2}{*}{$\begin{array}{l}\text { Bone defect } \\
1\end{array}$} & \multirow{2}{*}{$\begin{array}{l}\begin{array}{l}\text { Soft tissue } \\
\text { defect }\end{array} \\
0\end{array}$} \\
\hline Acute & Early & & & & & & \\
\hline Subacute & Delayed & Vasculopathy/neuropathy & Hand & $\mathrm{B}_{\mathrm{a}, \mathrm{c}, \mathrm{i}}$ & Gram- & 2 & $\mathrm{~cm}^{2} \mathrm{~B}$ \\
\hline \multirow[t]{7}{*}{ Chronic } & Late & Trauma & Long bones & $\mathrm{C}_{\mathrm{a}, \mathrm{c}, \mathrm{i}}$ & Mixed flora and/or multiresistant & $3 \mathrm{~A}, 3 \mathrm{~B}, 3 \mathrm{C}$ & $\mathrm{cm}^{2} \mathrm{~B}$ \\
\hline & & Temporary implant & Stage 1 & & Mycobacterium & & \\
\hline & & ICS classification & Stage 2 & & Fungi & & \\
\hline & & Type I & Stage 3 & & Negative & & \\
\hline & & Type II & Stage 4 & & & & \\
\hline & & Type III & Foot & & & & \\
\hline & & Permanent implant & Joint & & & & \\
\hline
\end{tabular}

4. Host type and age. Concerning age, the patient should be at least divided as infants ( $i,<2$ years of age), children (c, $<14$ years of age), adults ( $>14$ years of age), while host type is better defined, in our opinion, according to the classification proposed by McPherson [10].
Fig. 1 Percent of patients $(N=300)$ classified according to the items of the Seven-Item Comprehensive Classification System, treated consecutively for bone and joint infections in our department during the years 2008-2009

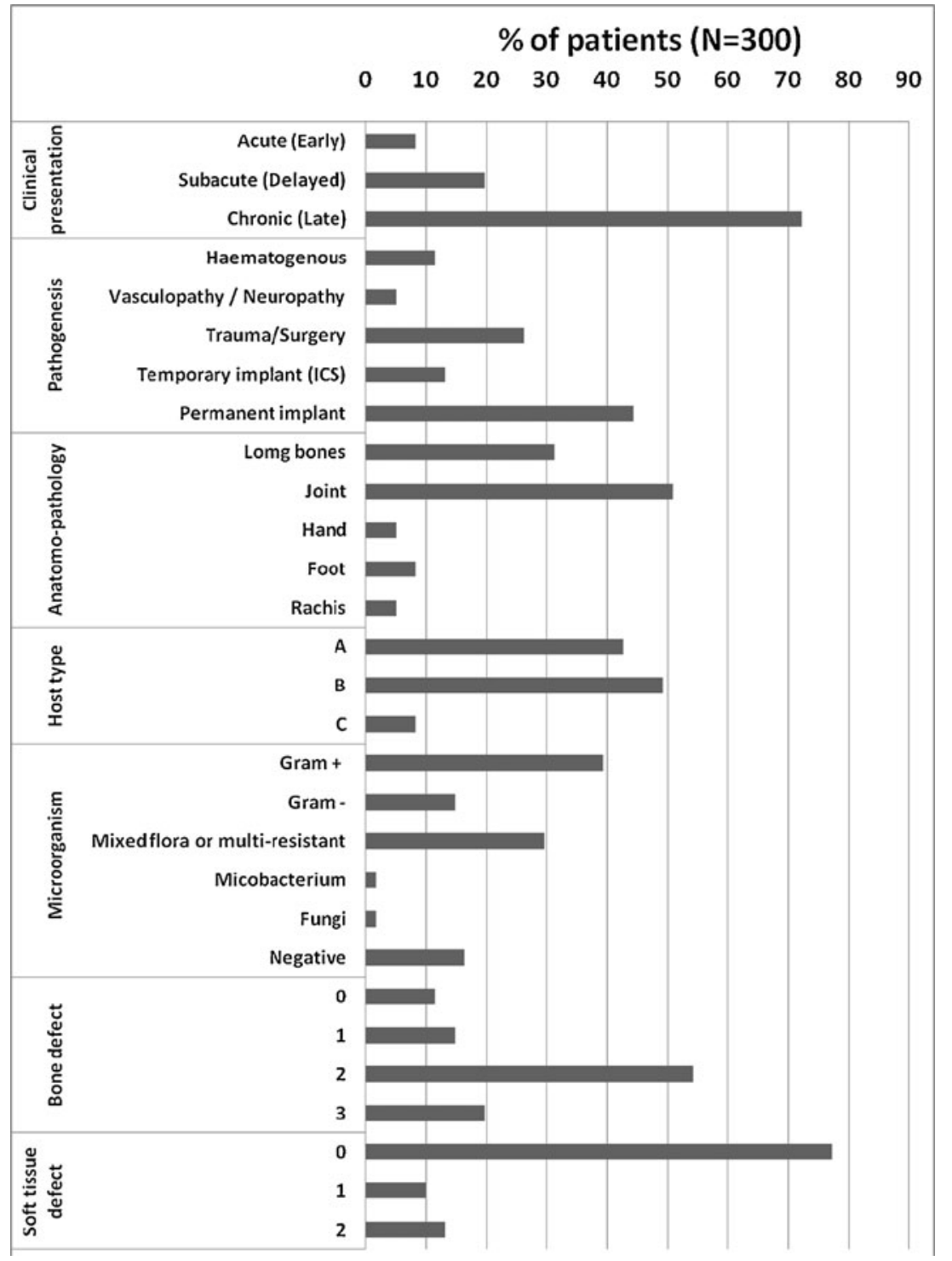


5. Microorganism(s) have been divided into gram-positive, gram-negative mycobacteria, and fungi and negative cultural examinations. A special section includes mixed flora and resistant bacteria. Each category requires a different medico-surgical approach and may have a different prognosis.

6. Bone defect is classified according to our proposal. Epiphyseal defects (type 2) may undergo a further categorization, applying the classification in use for bone loss associated with aseptic loosening of joint prosthesis [42-45].

7. Soft tissues are simply described as 0 , for no soft tissue defect, number of square centimeters of the soft tissue defect, if present, with a distinction between bone exposure (B) or not.

\section{Clinical testing of classifications}

Three hundred consecutive patients, affected by BJIs and treated surgically in our department in the years 2008-2009, have been classified according to the Seven-Item Comprehensive Classification System (Fig. 1). Chronic implant-related infections of the joints in B-type hosts with gram-positive germs and no soft tissue defects predominated in our experience. However, virtually all other types of BJIs were represented, with different frequency.

Figure 2 compares the respective ability of each of the ten retrieved classifications and of the 7 ICCS to classify the same cohort of 300 patients. While the comprehensive classification system was able to classify all the patients considered in the study, each classification could only describe, on the average, $34.8 \pm 24.7 \%$ of the patients affected by BJIs.

\section{Discussion}

Different classifications have been proposed in the last four decades to describe BJIs. However, each of them only focused on one nosological entity and examined one or few items. Due to a lack of a more ample and systematic approach, it is not possible, at present, to classify all the different types of BJIs, and this was confirmed in our study with an analysis of a consecutive series of non-selected patients referred to us for the treatment of BJIs.

To our knowledge, this is the first attempt to provide a comprehensive classification of all the patients affected by BJIs; the proposed classification system is mainly based on existing classifications that have been selected to describe, in each given subject, one or more of the seven items, individuated as necessary on the basis of an accurate literature research. In this way, the 7 ICCS provides a rather complete description of all the relevant features that may be found in a given patient affected by BJIs. The proposed system is intended for didactic and scientific purposes and may be potentially used to better compare patients and clinical series; however, it should be noted that the following limitations do apply to the system:

1. There is an objective lack of a modern, accepted classification of some of the relevant items (e.g., bone loss, soft tissue defects);
Fig. 2 Percent of patients that could be classified according to different available classifications and to the to Seven-Item Comprehensive Classification System

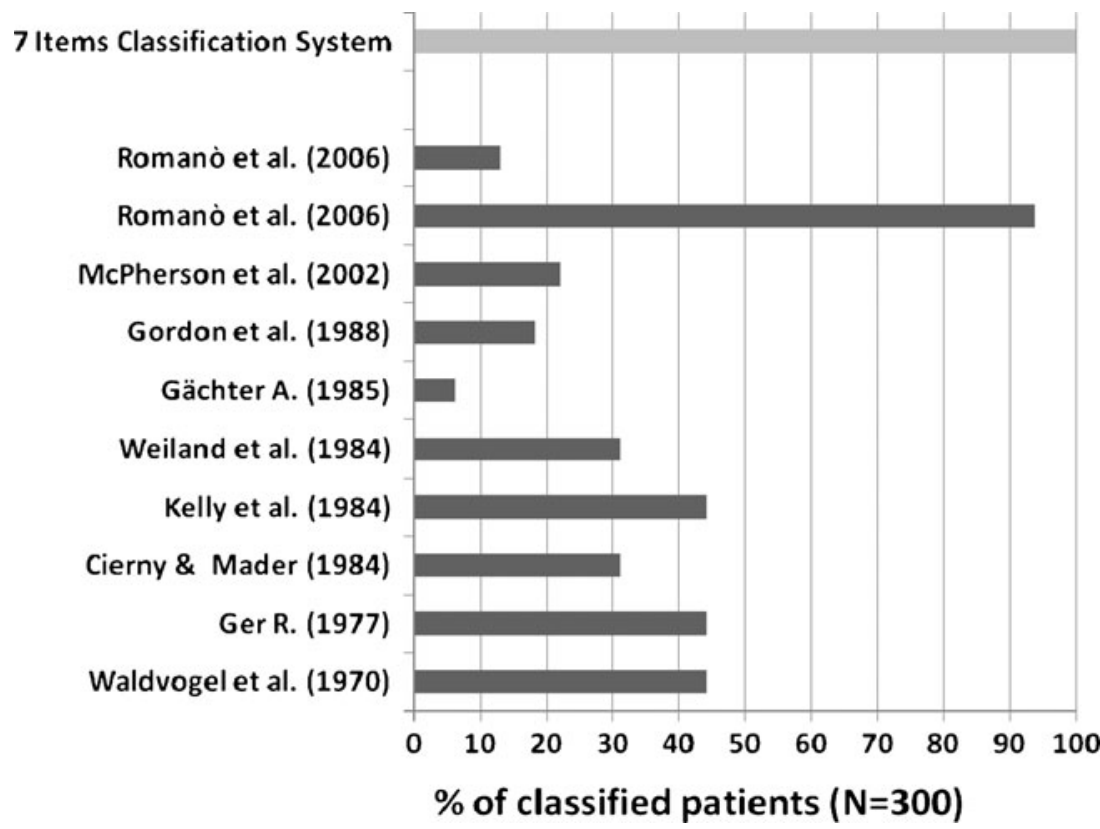


2. There is a lack of more specific subclassifications of some of the items. For example, infections of the hand, foot, and rachis have peculiar features, for which we decided to put apart from long bones and joint infections. However, there is no further classification of their anatomo-pathological aspect in infection, and this is probably a missing information;

3. The complexity of the system. A classification needs to be synthetic enough to be largely adopted while being sufficiently precise to serve as a basis for correct therapeutic decisions. In this case, we understand that some of the synthetic definitions of the clinical condition has been sacrificed to a more accurate description of the disease. This drawback appears as a difficult solution, given the particular nature of the infections of the skeletal system.

Competing interests The authors declare that they have no competing interests.

Open Access This article is distributed under the terms of the Creative Commons Attribution Noncommercial License which permits any noncommercial use, distribution, and reproduction in any medium, provided the original author(s) and source are credited.

\section{References}

1. Chassaignac E (1852) De l'osteomyelite. Bull Mem Soc Chir 431-436

2. Gristina AG, Costerton JW (1984) Bacterial adherence and the glycocalyx and their role in musculoskeletal infection. Orthop Clin North Am 15(3):517-535

3. Gristina AG, Shibata Y, Giridhar G, Kreger A, Myrvik QN (1994) The glycocalyx, biofilm, microbes, and resistant infection. Semin Arthroplasty 5(4):160-170

4. Levine SE, Esterhai JL, Heppenstall RB, Calhoun J, Mader JT (1993) Diagnoses and staging. Osteomyelitis and prosthetic joint infections. Clin Orthop Relat Res 295:77-86

5. Calhoun JH, Manring MM, Shirtliff M (2009) Osteomyelitis of the long bones. Semin Plast Surg 23(2):59-72

6. Cierny G 3rd, Mader JT, Pennick JJ (2003) A clinical staging system for adult osteomyelitis. Clin Orthop 414:7-24

7. Mader JT, Shirtliff M, Calhoun JH (1997) Staging and staging application in osteomyelitis. Clin Infect Dis 25:1303-1309

8. Waldvogel FA, Medoff G, Swartz MN (1970) Osteomyelitis: a review of clinical features, therapeutic considerations and unusual aspects (first of three parts). N Engl J Med 282:198-206

9. Cierny G 3rd, DiPasquale D (2002) Periprosthetic total joint infections. Staging, treatment, and outcomes. Clin Orthop Relat Res 403:23-28

10. McPherson EJ, Woodson C, Holtom P, Roidis N, Shufelt C, Patzakis M (2002) Periprosthetic total hip infection. Outcomes using a staging system. Clin Orthop Relat Res 403:8-15

11. Der Gelenkinfekt GA (1985) Inf Arzt 6:35-43

12. Lew DP, Waldvogel FA (2004) Osteomyelitis. Lancet 364 (9431):369-379
13. Tsukayama DT, Estrada R, Gustilo RB (1996) Infection after total hip arthroplasty. A study of one hundred and six infections. J Bone Joint Surg Am 78:512-523

14. Widmer AF (2001) New developments in diagnosis and treatment of infection in orthopedic implants. Clin Infect Dis 33:S94-S106

15. Zimmerli W (1999) Prosthetic device infections. In: Root RK, Waldvogel FA, Corey L, Stamm WE (eds) Clinical infectious diseases: a practical approach. Oxford University Press, Oxford, pp 801-808

16. Carek PJ, Dickerson LM, Sack JL (2001) Diagnosis and management of osteomyelitis. Am Fam Physician 63(12):24132420

17. Nelson JP (1977) Deep infection following total hip arthroplasty. J Bone Joint Surg Am 59:1042-1044

18. Schmalzried TP, Amstutz HC, Au MK, Dorey FJ (1992) Etiology of deep sepsis in total hip arthroplasty. The significance of hematogenous and recurrent infections. Clin Orthop Relat Res 280:200-207

19. Kelly PJ (1984) Infected nonunion of the femur and tibia. Orthop Clin North Am 15:481-490

20. Berendt AR, Lipsky B (2004) Is this bone infected or not? Differentiating neuro-osteoarthropathy from osteomyelitis in the diabetic foot. Curr Diab Rep 4(6):424-429

21. Romanò C (2009) Infezioni osteo-articolari correlate all'impianto. Numero monografico de Lo Scalpello 23-3

22. Meani E, Romanò CL, Crosby L, Hofmann G (2007) Infection and local treatment in orthopaedic infections. Springer, Heidelberg

23. Gristina AG, Naylor P, Myrvik Q (1989) Infections from biomaterials and implants: a race for the surface. Med Prog Technol 14:205-224

24. Romanò CL, Zavatarelli GA, Tinti M (2006) Meani E Profilassi dell'infezione nell'osteosintesi e classificazione "ICS" come guida al trattamento. Arch Ortop Reumatol 117(3):8-11

25. Court-Brown CM, Keating JF, McQueen MM (1992) Infection after intramedullary nailing of the tibia. Incidence and protocol for management. J Bone Joint Surg Br 74(5):770-774

26. Green SA, Larson MJ, Moore TJ (1987) Chronic sepsis following intramedullary nailing of femoral fractures. J Trauma 27(1):5257

27. Laky R (1989) Results of treatment of infected osteosynthesis cases. Magy Traumatol Orthop 32(3):187-193

28. Romanò C, Logoluso N (2009) Low intensity pulsed ultrasound for the treatment of bone delayed union or nonunion: a review. Ultrasound Med Biol 35(4):529-536

29. Weiland AJ, Moore JR, Daniel RK (1984) The efficacy of free tissue transfer in the treatment of osteomyelitis. J Bone Joint Surg Am 66:181-193

30. Cierny G, Mader JT, Penninck JJ (1985) A clinical staging for adult osteomyelitis. Cont Orthop 10:5

31. Anagnostakos K, Schmid NV, Kelm J, Grün U, Jung J (2009) Classification of hip joint infections. Int J Med Sci 6(5):227233

32. Romanò CL, Logoluso N, Elia A, Romanò D (2010) Osteomyelitis in elderly patients. BMC Geriatr 10(Suppl 1):L15

33. Cierny G, Mader JT (1984) Adult chronic osteomyelitis - an overview. Orthopedics 7(10):1557-1564

34. Ure KJ, Amstutz HC, Nasser S, Schmalzried TP (1998) Directexchange for the arthroplasty treatment of infection after total hip arthroplasty. J Bone Joint Surg Am 80:961-968

35. Kilgus DJ, Howe DJ, Strang A (2002) Results of periprosthetic hip and knee infections caused by resistant bacteria. Clin Orthop Relat Res 404:116-124

36. Lazzarini L, Manfrin V, De Lalla F (2004) Candidal prosthetic hip infection in a patient with previous candidal septic arthritis. J Arthroplasty 19:248-252 
37. Calhoun JH, Mader JT (1989) Antibiotic beads in the management of surgical infection. Am J Surg 157:443-449

38. Anthony JP, Mathes SJ, Alpert BS (1991) The muscle flap in the treatment of chronic lower extremity osteo-myelitis: results in patients over 5 years after treatment. Plast Reconstr Surg 88:311-318

39. Beris AE, Soucacos PN, Xenakis TA (1995) Latissimus dorsi free transfer for coverage of extensive soft tissue defects. Acta Orthop Scand 264:31-34

40. Lazzarini L, Mader JT, Calhoun JH (2004) Osteomyelitis in long bones. J Bone Joint Surg Am 86:2305-2318

41. Papineau LJ, Alfageme A, Dalcourt JP (1979) Osteomyelite chronique: excision et greffe de spongieux a l'air libre apres mises a plat extensives. Int Orthop 3:165-176. 20

42. D'Antonio JA, Capello WN, Borden LS, Bargar WL, Bierbaum BF, Boettcher WG, Steinberg ME, Stulberg SD, Wedge JH (1989) Classification and management of acetabular abnormalities in total hip arthroplasty. Clin Orthop Relat Res 243:126-137

43. D'Antonio J, McCarthy JC, Bargar WL, Borden LS, Capello WN, Collis DK, Steinberg ME, Wedge JH (1993) Classification of femoral abnormalities in total hip arthroplasty. Clin Orthop Relat Res 296:133-139

44. Della Valle CJ, Paprosky WG (2003) Classification and an algorithmic approach to the reconstruction of femoral deficiency in revision total hip arthroplasty. J Bone Joint Surg Am 85(suppl 4):1-6

45. Paprosky WG, Bradford MS, Younger TI (1994) Classification of bone defects in failed prostheses. Chir Organi Mov 79:285-291

46. Gordon L, Chiu EJ (1988) Treatment of infected non-unions and segmental defects of the tibia with staged microvascular muscle transplantation and bone-grafting. J Bone Joint Surg Am 70:377386

47. Romanò CL, Meani E (2006) Il difetto osseo nelle infezioni: proposta di classificazione e opzioni di trattamento. Arch Ortop Reumatol 117:14-15

48. Calhoun JH, Anger DM, Mader JT (1991) The Ilizarov technique in the treatment of osteomyelitis. Tex Med 87:56-59

49. Ger R (1977) Muscle transposition for treatment and prevention of chronic traumatic osteomyelitis of the tibia. J Bone Joint Surg Am 59:784-791 